Ann. Génét. Sél. anim., I973, 5 (3), 403-4Io.

\title{
THE CONSEQUENCES OF SELECTION FOR SHELL QUALITY IN POULTRY ( $\left.{ }^{1}\right)$
}

\author{
W. F. van TIJEN \\ Institute for Poultry Research " Het Spelderholt", \\ Beekbergen, The Netherlands
}

\section{SUMMARY}

In two strains, one of White Leghorns, the other of Rhode-Island Red three generations of selection for raising egg-shell quality traits gave a positive result for the selected trait, but a detrimental correlated response for characters of laying intensity and egg weight, as compared to a control population in each case.

The following is a report on a selection experiment with regard to shell quality which we carried out at our Institute. After we had found a heritability for deformation of 0.32 and 0.40 for out White Leghorn and Rhode Island Red strain respectively - as an average over 6 generations - we wanted to see what would happen when we actually were going to select for the strength of the shell. Basically the project was set up to find the answer to two questions : firstly : what are the possibilities of improving shell quality by means of selection? Secondly : what happens with other traits - like production, egg weight and other egg quality factors - when a one-sided selection for shell quality is practised?

The following are some particulars about the animal material which was used. As already mentioned it consisted of a White Leghorn and a Rhode Island Red strain which in I959 had been bought from private breeders and which were known as Babcock and Parmenter respectively.

There were strong reasons to believe that they had been bred as closed groups before that time. After they had been obtained they were bred as closed groups with a mild selection pressure on production, shell quality and internal quality. Inbreeding did not amount to more than one percent per year. The above mentioned

(1) Cet article a été présenté à la réunion du groupe de travail no 3 (Sélection et Testage) de la Fédération des Branches européennes de la W. P. S. A., Nouzilly-Ploufragan, 6-1o septembre 197x. 
procedure was followed in the years I96I-I966 and the data were used to estimate as many genetic parameters about production and egg quality as possible. First of all heritabilities - of which those for deformation have been already mentioned above - and secondly phenotypic and genetic correlations between productivity and egg quality traits and between egg quality factors mutually - were determined (VAN TIJEN and KUIT, I970). The estimates about phenotypic and genetic correlations in this report led to the conclusion that it should be possible to breed for shell quality without detriment to the productivity traits.

In 1967 the above mentioned strains were each divided into two genetically equal substrains $\mathrm{A}$ and $\mathrm{B}$. This was done in the following way : for the breeding of the first generation 20 cocks were used. Each of these was mated to 12 hens which two by two were full sisters of each other. The progeny of the one sister was allotted to strain $\mathrm{A}$, that of the other sister to strain $\mathrm{B}$.

Each of the four strains consisted of about 500 hens. Thereafter, starting in I 968 , the number of hens per strain was raised to $75^{\circ}$.

In the following years (I968, I969 and r970) both A strains, which we shall designate as shell strain, were selected solely for shell quality while for the B strains (the " production strain ") a more traditional selection system was followed.

The selection took place after a comparatively short period of production when the hens had reached an age of 38 weeks). The egg quality was measured at the age of 30 weeks. The final production data - the total numbers of eggs and the laying percentage per surviving hen ad per hen present - were determined at the age of 72 weeks, while a second measurement of the egg quality was taken at the age of 60 weeks.

The egg quality, shape index, shell quality and internal quality, height of thick albumen in mm and blood- and meatspots were determined on samples of four eggs per hen as much as possible. Shell quality was measured in three different ways, namely:

a) shell thickness in $0.0 \mathrm{Im}$ measured at two places at the waist;

b) the specific gravity of the whole egg;

c) the shell stiffness - the deformation of the shell under a load of $500 \mathrm{~g}$ - in $0.00 x$ of a mm.

From these three measurements an index for the shell quality was calculated in which each was represented for an equal part.

The production strains were also selected on the basis of an index in which four traits were represented : production for $5^{\circ} \mathrm{p}$. IOo, egg weight for $30 \mathrm{p}$. IOO and shell and internal quality each for ro p. roo. Both indexes are given in table I.

The results of this selection experiment are given at the moment the third selected generation has about reached the age of 72 weeks. The Rhode Island Red strains are not quite that old, but it was possible to make a quite accurate estimation.

A few essential data which show the difference which has arisen between the shell and the control strain after three years of selection are given in table 2 . A more elaborate set of figures will be found in table 3 .

Bearing in mind that the strains in 1967 had been started at an approximate equal level, the shell strain has reacted up on the selection pressure which has been exerted on shell quality. We did obtain eggs with a stronger shell. This selection has 
had its consequences however for the productivity traits. Compared with the more traditionally selected production strain the number of eggs and the egg weight has clearly remained behind. It also seems that the relatively small selection pressure (Io p. Ioo of the total) on the internal quality has had its effects.

\section{TABLE I}

The shell quality and the production index which were used to select for shell quality and productivity traits respectively (see text)

Index de qualité de coquille et de production utilisées respectivement pour sélectionner la qualité de la coquille et les caractères de productivité

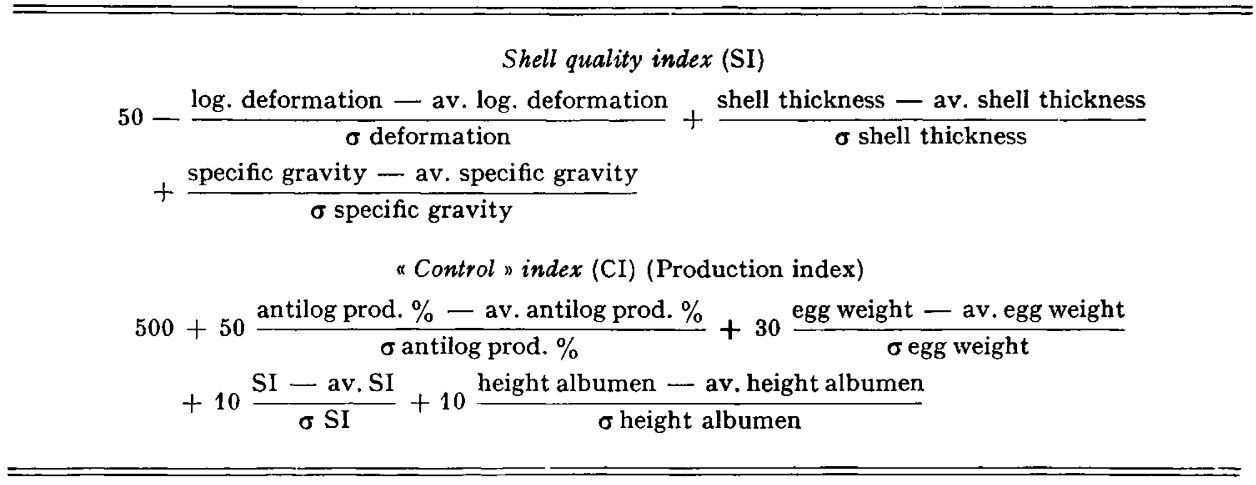

TABLE 2

Differences between the shell and the control groups after 3 years of selection for shell quality

Différences entre les groupes "coquille " et "contrôle " après 3 années de sélection pour la qualité de la coquille

\begin{tabular}{|c|c|c|c|}
\hline & W.L. & R.I.R. & Average \\
\hline \multicolumn{4}{|l|}{ Trait } \\
\hline No. of eggs 72 weeks $\ldots \ldots \ldots \ldots$ & -12 & -8 & -10 \\
\hline Average egg weight $\ldots \ldots \ldots \ldots$ & -1.9 & -3.6 & -2.8 \\
\hline Egg weight 60 weeks $\ldots \ldots \ldots \ldots$ & -2.9 & -3.9 & -3.4 \\
\hline Grammes of egg per hen present.. & -1149 & -1170 & -1159 \\
\hline Egg quality 60 weeks & & & \\
\hline Defomation $(0.001 \mathrm{~mm}) \ldots$ & -1.8 & -2.4 & -2.1 \\
\hline Specific gravity $\ldots \ldots \ldots \ldots$ & +4.9 & +4.3 & +4.6 \\
\hline Shell thickness $(0.01 \mathrm{~mm}) \ldots \ldots$ & +2.0 & +1.4 & +1.7 \\
\hline Albumen height $(0.1 \mathrm{~mm}) \quad \ldots \ldots$ & -76 & -50 & -62 \\
\hline
\end{tabular}

The frequency distributions of some shell quality traits are also illustrative in this respect (fig. I and 2). They only concern the shell strains. The deformation has a skew distribution with a tail to the right. It has in the course of the years 


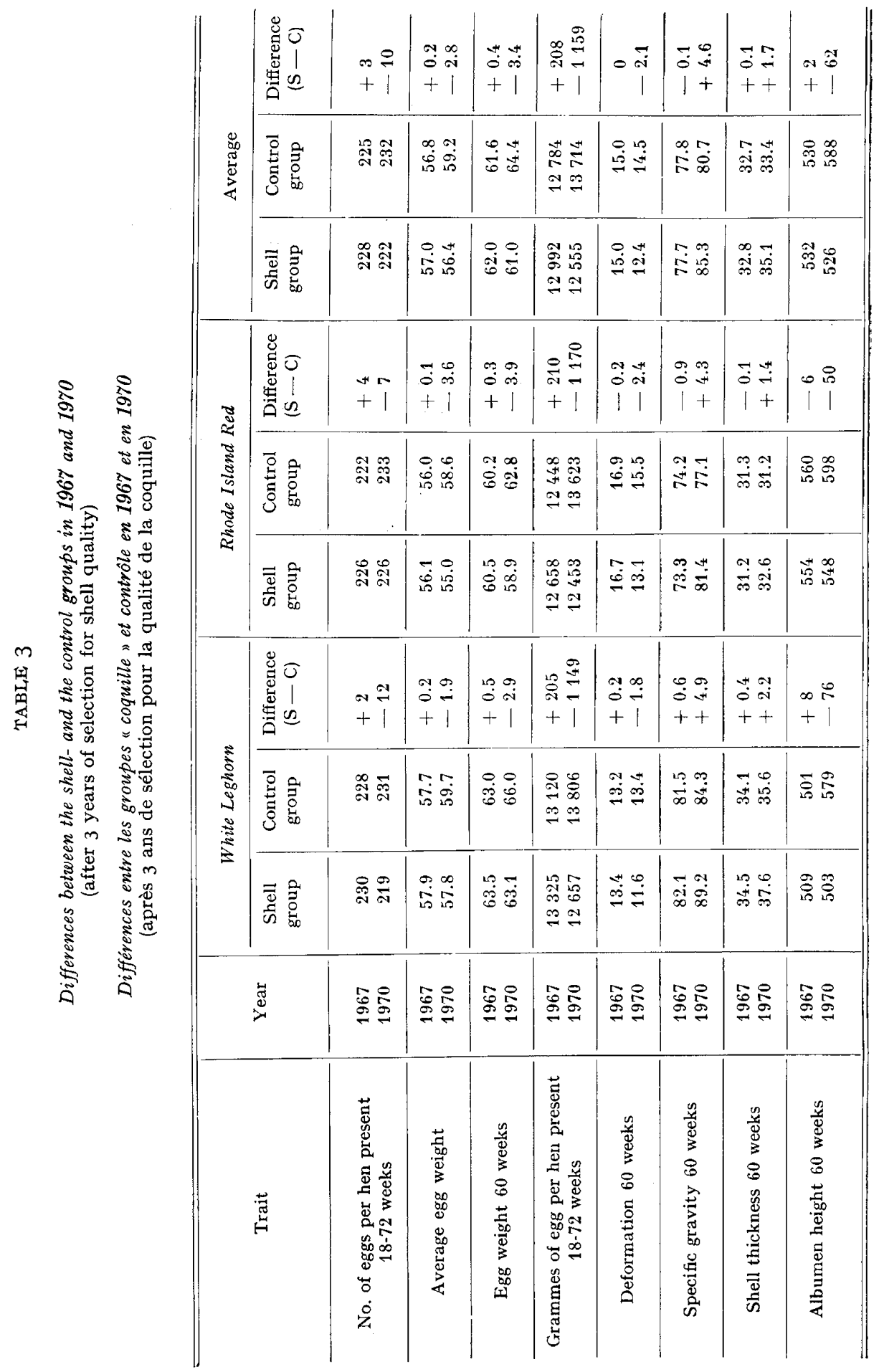


clearly shifted to the left in the direction of a better shell. The long tail at the right end (the very poor quality shells) seems to have disappeared. Furthermore the variation of the distributions seems to have become smaller. The distribution of the specific gravity is of a more normal character, has shifted to the right and the variation has about remained the same.

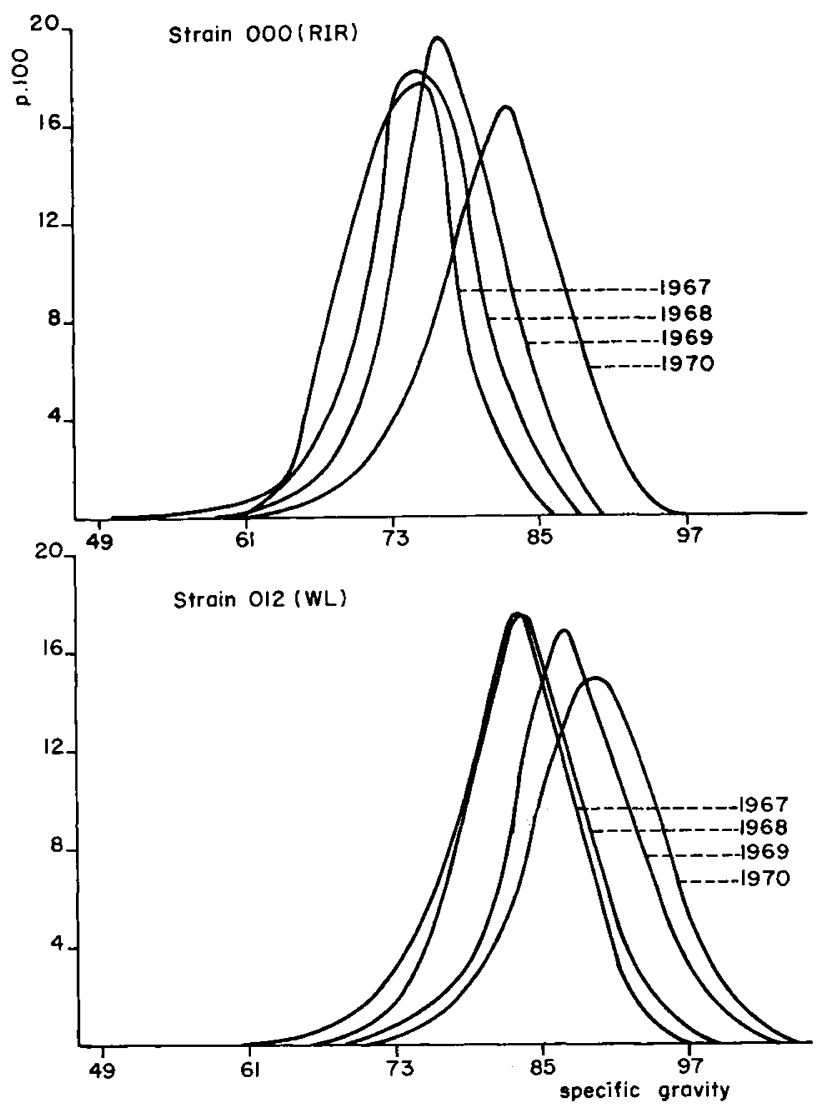

FIG. I. - Frequency distribution of specific gravity in two strains in the course of 3 years one sided selection for shell quality

Distribution de fréquence du poids spécifique dans deux lignées au cours de 3 ans de sélection unilatérale pour la qualité de la coquille

It is also interesting to look into the matter of the selection differential. With the comparatively recent data at our disposal it was not possible to look into the matter extensively. However for one or two traits the following can be said : It is proposed to take egg weight and deformation as productivity and shell quality trait respectively.

Looking at the cumulative selection differential over the period $1967-1970$ during which this selection experiment has been carried out, a response by multiplying the selection differential by the heritability can be predicted. As an average of the latter the mean found in the years I96I-I966 was taken. This predicted res- 
ponse was then compared with the realized one which give the results given in table 4 .

The data are to be considered preliminary ones, as there was no opportunity to weigh the differential according to number of offspring per dam. For the trait early egg weight - egg weight at 30 weeks of age - the White Leghorn control

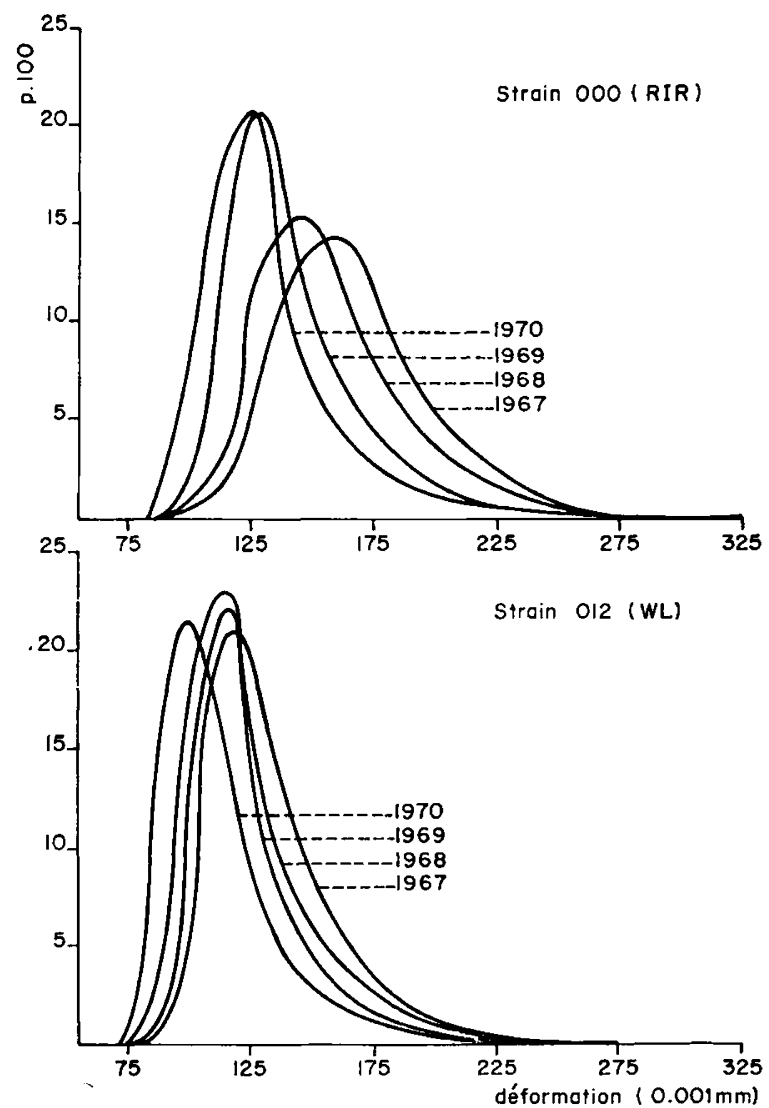

FIG. 2. - Frequency distributions of deformation in two strains in the course of 3 years one sided selection for shell quality

Distribution de fréquence de la déformation dans deux lignées au cours de 3 ans de sélection unilatérale pour la qualité de la coquille

strain showed a predicted response of 2.7 grams against a realized response of 3.6 grams. The shell strain showed a small correlated response of 0.7 grams against a realized one of $\mathrm{I} .6$ grams. For the Rhode Island Reds these figures were respectively $+4.6,+3.7,+0.7$ and - o.4. Likewise for deformation we found for the White Leghorn shell strain a predicted response of $-\mathrm{I} .8 \mu$ against a realize done of $-3.5 \mu$. The control strain again in which there was a ro $p$. Ioo selection pressure on shell quality showed a predicted response of -0.4 against a realized one of - 2.2 $\mu$. For the Rhode Island Reds again these figures were respectively $-\mathbf{2 . 3}$, $-490-0.6$ and -2.5 .

The differences between the predicted and the realized response in the two 


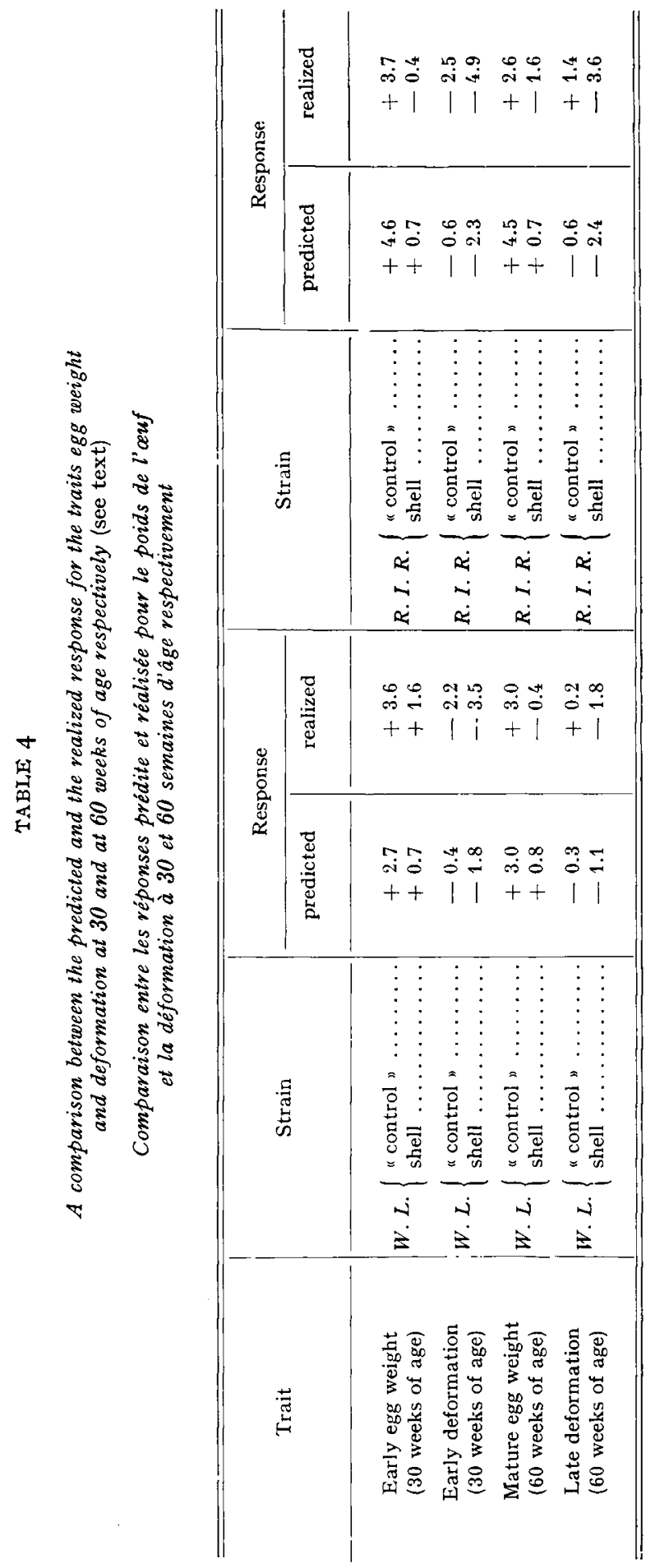


strains turn out to be about the same. Considering the variability of the estimation of the heritability prediction and actual result seems to be fairly well in agreement with each other.

For egg weight and deformation at 60 weeks of age - this response is correlated, as we selected at 30 and not at 60 weeks of age - the differences between predicted and realized response in the two strains are larger.

Summing up, the results merit the conclusion that the improvement of shell quality by means of breeding, in other words the inclusion of favourable genes for this trait in the genetic pattern of the chicken, is very well possible. We must realize ourselves however that in some cases there is a chance that the productivity will decrease. This is a minus point which we will have to weigh against the improvement in shell quality.

The question is if the lower percentage of broken eggs resulting from the better shell equals the lesser amount of eggs which we have a chance of collecting when we practize a one-sided selection for shell quality. A calculation in this respect is not simple because so many variables have their effect.

If we consider the complete chain from producer to consumer we can think of the way in which a hen lays an egg, the way of housing, the way of collecting, packing material, treatment at the packing station, etc.

In considering the curve, which expresses the relation between for example specific gravity and breakage during transport, we see that it is not linear. If we look at the higher specific gravities we see that a further improvement has only very little effect. However, we should realize ourselves that this curve only concerns the transport phase in a special case. All the other factors mentioned above are not considered here.

In general it can be said that only in the case of definitely poor quality shells it seems to be worthwhile to exert a strong selection pressure for shell quality. It looks as if very soon the loss in productivity will outweight the lesser breakage on account of the improved shell strength.

Reçu pour publication en avril 1973.

\author{
RÉSUMÉ \\ LES CONSÉQUENCES DE LA SÉLECTION \\ POUR LA QUALITÉ DE LA COQUILLE CHEZ LA POULE
}

Dans deux lignées, l'une de Leghorn Blanche, l'autre de Rhode-Island, trois générations de sélection pour augmenter la qualité de la coquille des œufs ont abouti à un résultat positif, mais ce, au détriment des caractères d'intensité de ponte et de poids des œufs, comparativement à une population témoin dans chaque cas.

\title{
RÉFÉRENCES BIBLIOGRAPHIQUES
}

TIJEN W.F. VAN, Kuit A. R., I970. The heritability of characteristics of egg quality, their mutual correlation and the relationship with productivity. Arch. Gefliugelk., 6, 201-210. 